\title{
A crise e a cidade no Brasil
}

Ariane Melchior Nunes da Horta and Guilherme Chalo Nunes

\section{(2) OpenEdition}

\section{Journals}

Electronic version

URL: http://journals.openedition.org/espacoeconomia/2371

DOI: 10.4000/espacoeconomia.2371

ISSN: 2317-7837

\section{Publisher}

Núcleo de Pesquisa Espaço \& Economia

\section{Electronic reference}

Ariane Melchior Nunes da Horta and Guilherme Chalo Nunes, «A crise e a cidade no Brasil », Espaço e Economia [Online], 9 | 2016, Online since 04 January 2017, connection on 23 September 2020. URL : http://journals.openedition.org/espacoeconomia/2371 ; DOI : https://doi.org/10.4000/ espacoeconomia.2371

This text was automatically generated on 23 September 2020 .

(C) NUPEE 


\section{A crise e a cidade no Brasil}

Ariane Melchior Nunes da Horta and Guilherme Chalo Nunes

\section{REFERENCES}

MARICATO, Ermínia Para entender a crise urbana. São Paulo: Expressão Popular, 2015.

Capa

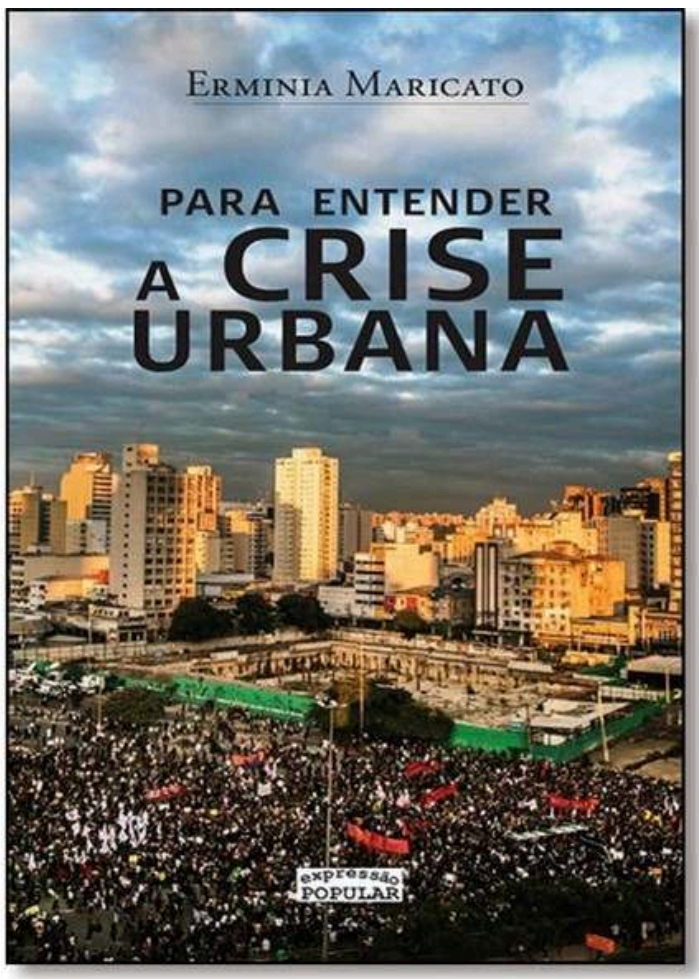

Imagem da capa 
1 O livro Para entender a crise urbana (2015), da urbanista e professora titular da Universidade de São Paulo Ermínia Maricato, apresenta a complexidade do urbano e os caminhos do direito à cidade no Brasil. Os textos presentes no livro, dentre eles um redigido no calor das Jornadas de Junho de 2013, correspondem a um chamado a pensar que percursos as cidades brasileiras estão trilhando nos últimos anos, e ao mesmo tempo, o livro é um convite a reflexão sobre reforma urbana, como um paradigma político para a ação.

2 O fundamental texto para quem quer pensar as cidades brasileiras é composto por três artigos, e mais uma entrevista, que, compilados pela Editora Expressão Popular, nos apresenta uma rica contribuição para a reflexão sobre o desenvolvimento desigual do capitalismo e a sua forma de (re)produção através do espaço urbano (SMITH, 1988).

3 Segundo a autora, este livro contribui para erradicar o analfabetismo urbanístico ${ }^{1}$ - um conceito desenvolvido a partir da sua experiência e que salienta a ignorância de uma grande parte da população sobre os processos políticos e econômicos que circundam a gestão e a economia urbana. o livro afasta simplificações e nos mostra a complexidade dos problemas que a cidade contemporânea brasileira nos coloca.

4 Do planejamento urbano na era da globalização, passando pela urbanização brasileira e os conflitos e remoções no centro da cidade de São Paulo, a autora aborda a crise urbana tangenciando sua aparência em várias escalas da produção do espaço para compreender os mecanismos políticos econômicos que a engendram.

5 A partir de sua experiência política e intelectual, o texto é capaz de sintetizar temas centrais para o pensamento urbano contemporâneo nas páginas que compõem o livro. Ermínia Maricato dialoga por grandes referências do urbanismo, como Carlos Vainer, Otília Arantes e Mike Davis; da geografia, como David Harvey, Neil Smith e Milton Santos; da arquitetura, como Flávio Villaça e Sergio Ferro; e da sociologia, como Francisco de Oliveira, Florestan Fernandes e Celso Furtado. A autora ainda discute sua própria experiência acadêmica, revisitando seus próprios textos, e sua experiência política como formuladora de projetos urbanos. Em particular, aqui ela incorpora sua participação na criação do Ministério das Cidades, no primeiro mandato na Presidência da República do Partido dos Trabalhadores, no ano de 2003.

6 No primeiro capítulo, intitulado "Cidades e a luta de classes no Brasil”, a autora apresenta as características da urbanização brasileira, debatendo seu desenvolvimento histórico e suas contradições, principalmente as características que as cidades brasileiras desenvolveram nos primeiros anos do século XXI, pautados pela política urbana desenvolvida pelos programas do Partido dos Trabalhadores. A autora pensa os fenômenos contemporâneos como hegemonia, alienação e (re)produção do capitalismo, a partir da cidade; afinal, o modo de vida urbano se tornou massificado mundialmente a partir da primeira década do século XXI, de maneira que hoje mais da metade da população mundial vive no ambiente construído das cidades.

7 Para refletir a crise urbana que se apresenta na virada do século no Brasil e no mundo, a autora parte da abordagem marxista sobre os conflitos do espaço urbano apresentando a especificidade desta mercadoria que é a terra urbana, que

é um produto resultante de determinadas relações de produção. Se lembrarmos que a terra urbana, ou um pedaço da cidade, constitui sempre uma condição de monopólio - ou seja, não há um trecho ou terreno igual a outro, e a sua localização não é reproduzível - estamos diante de uma mercadoria especial que tem o atributo de captar ganhos sobre a forma de renda (MARICATO, 2015, p. 23). 
8 A cidade como locus da (re)produção do capitalismo e como os agentes do capital moldam o ambiente construído das cidades para valorizar ao máximo seu capital e sua renda. Ermínia Maricato fundamenta-se nos conceitos de reprodução simples, reprodução ampliada, renda fundiária e terra-localização para apreender conceitualmente esse grande movimento contraditório que é a produção do espaço urbano no Brasil hoje. Onde a mercantilização da terra, a especulação imobiliária e a financeirização da moradia são marcas cada vez mais presentes (ROLNIK, 2015).

9 A autora reflete sobre o processo de urbanização brasileira a partir de uma periodização, onde ela observa que o capitalismo no Brasil e na periferia mundial apresentam características históricas diferentes. Não podemos pensar esse processo sem pensar a característica específica do desenvolvimento histórico do capitalismo no Brasil como "modernização do atraso". Por meio do trabalho de Francisco de Oliveira (2003) sobre este processo, Maricato define o contexto de urbanização/industrialização brasileira como "urbanização dos baixos salários", com o desenvolvimento de autoconstrução de casas como um fenômeno central nesse processo; fenômeno que persiste na paisagem das cidades brasileiras até os dias de hoje, e é fundamental para a dinâmica de exploração do trabalho nas cidades, devido ao baixo custo de reprodução da força de trabalho.

10 Essa característica histórica brasileira foi aprofundada nos anos neoliberais ${ }^{2}$, onde houve um aumento do desemprego e a queda do investimento público em políticas de bem estar, que deu forma ao ambiente de segregação e crise urbana que vivemos hoje nas cidades brasileiras. A conclusão é que "as três políticas públicas urbanas estruturais (ligadas à produção do ambiente construído) - transporte, habitação e saneamento foram ignoradas, por mais de 20 anos".

11 Já no segundo capítulo, intitulado "Terror imobiliário ou a expulsão dos pobres do centro de São Paulo", a autora apresenta uma abordagem crítica da gestão urbana, onde ela mostra as contradições da maior cidade da América Latina. Em São Paulo, a população pobre e trabalhadora está sofrendo um processo de remoção da área central, que é disputada por grupos de especuladores imobiliários, movimentos sociais, a Prefeitura de São Paulo e comerciantes locais.

12 O centro de São Paulo é a chave do acesso ao resto da cidade, tendo o metrô, linhas de trem e ônibus que ligam a área a toda grande São Paulo. Com isso, esforços por meio de políticas de renovação dos governos do PSDB (José Serra e Gilberto Kassab) são feitos para uma revalorização do solo, como investimentos culturais, projetos que visaram levar ao espaço urbano do centro novos olhares. A questão principal que a autora nos traz é: estes projetos visam a expulsão dos pobres do centro e a renovação destas áreas, para venda e novos investimentos em prédios e terrenos. Mas com isso, para onde vão estas pessoas que ali residem?

13 São Paulo vive uma bolha especulativa no mercado imobiliário; para muitos é impossível viver em outro bairro da cidade em sua região central, tendo assim que migrar para a periferia da cidade, longe de seu trabalho e dos meios de transporte rápidos. O centro da cidade oferece maiores oportunidades de emprego, lazer e educação, contando com grandes universidades.

14 Ermínia Maricato mostra que uma das soluções encontradas, já que a população pobre que ali vivia não aceitava sair, foi o uso da violência. Muitos incêndios foram registrados nesta região, como também implosões de prédios realizados pela prefeitura, 
na qual se sabia que havia pessoas próximas, correndo riscos. A 'higienização' do centro da cidade no trato com os dependentes químicos também foi uma prática nesta gestão tucana, usando a polícia como motor principal deste plano: ao invés de tratar os dependentes como um problema de saúde pública, eles foram alvo de criminalização. A autora nos mostra que a única forma da garantia da habitação popular na área central da cidade seria implementar o Estatuto da Cidade em sua forma integral, que sugere o uso de imóveis abandonados como moradia social.

Na gestão de Fernando Haddad alguns prédios foram entregues as populações de baixa renda residentes da área central e ao Movimento dos Trabalhadores Sem Teto, como moradia social, inclusive em áreas centrais; percebe-se que o caminho a se seguir é o da inclusão e da garantia da habitação como direito.

16 As cidades sempre tiveram um papel fundamental no desenvolvimento do capitalismo, funcionando como grandes centros de expansão absoluta a partir de um ciclo de modernização constante ${ }^{3}$. Com o processo de globalização as cidades reforçam o seu protagonismo com processo de desindustrialização e financeirização da economia, transformando-se neste período em grandes centros financeiros e culturais onde os serviços e os grandes eventos passam a ter cada vez mais importância na economia urbana dos países centrais ${ }^{4}$. O processo de globalização e fundamentalmente esse processo nos países periféricos e o plano e fundo do terceiro capitulo do livro, intitulado "Globalização e a política urbana na periferia do capitalismo".

o discurso neoliberal - a face ideológica do processo de globalização - cresce cada vez mais e vai tomando conta das políticas públicas dos Estados, enfraquecendo os direitos conquistados ao longo dos anos de bem-estar social, desregulando a economia e tornando-a cada vez mais financeirizada; gerando desemprego, ataques a sindicatos, financeirização de políticas públicas etc. Entretanto, esse é um fenômeno desigual (SMITH, 1988). Nos países centrais, principalmente na Europa e nos EUA, observamos claramente uma economia em reestruturação produtiva; porém esta não é uma realidade mundial por completo, apesar dessa dinâmica afetar todo o globo. Nos países periféricos, o processo de globalização significou integração ao mercado mundial, mesmo que de maneira subalterna aos grandes centros financeiros mundiais perpetuando a histórica condição de dependência econômica.

Junto a este processo, a configuração dos países periféricos, que tem o passado colonial como base, nos ajuda a entender a dificuldade de implementação de políticas inclusivas e democráticas: a longa tradição patrimonialista e latifundiária dá ao poder sobre a terra um papel fundamental nessas formações sociais que permanece até os dias de hoje.

"A história da formação da sociedade nacional latino-americana é a história de uma longa luta pela terra. No primeiro dia, todos ouviram o grito: - Terra à vista! No depois, sempre, há colonização bandeirismo, pioneirismo, busca do ouro, coleta de especiarias, escambo com os nativos, donatárias, sesmarias, escravização do índio e do negro, economia primária exportadora, enclave, industrialização substitutiva de importações, associações de capitais, latifúndio, fazenda, plantação, engenho, estrada, rodovia, barragem, agroindústria, fabrica, cidade. Sempre se repete o grito: - Terra à vista!" (IANNI, 1988)

Esse contexto nos ajuda a compreender a modernização do atraso que engendrou as cidades dos países periféricos.

20 A última parte do livro é uma entrevista que a autora concedeu em 2014, tentando compreender os movimentos sociais que emergiram nas manifestações das jornadas de 
junho de 2013. Com pauta baseada em vários temas relacionados à questão urbana, como por exemplo a mobilidade, podemos compreender aquele movimento contestatório; a princípio, como o fruto da crise urbana.

21 Maricato faz uma dura crítica à política urbana desenvolvida a partir do segundo governo do Partido dos Trabalhadores, posto que esta foi subsumida aos dois programas principais - Minha Casa Minha Vida e Programa de Aceleração do Crescimento - e aos investimentos em grandes eventos como a Copa do Mundo (2014) e aos Jogos Olímpicos (2016).

Estas políticas anticíclicas, isto é, que foram implementadas para enfrentar a crise, impactam o espaço urbano diretamente e foram pensadas em grande parte pelo grande capital imobiliário e as grandes empreiteiras, que são os principais financiadores do sistema político brasileiro - assim a política urbana se transforma em um impasse ${ }^{5}$. Onde antes havia movimentos organizados pela reforma urbana construindo políticas públicas nesta direção, como no Ministério das Cidades e em algumas prefeituras no Brasil, agora a ideia de reforma urbana é solapada por cidades-palco de grandes projetos de uma política urbana voltada para a especulação imobiliária, para a financeirização da habitação e para segregação; cunhados pelo compadrio e pelo patrimonialismo e formatados para as relações promíscuas com empreiteiras e com o mercado imobiliário, aos movimentos sociais, cabe o estigma da criminalização.

No modelo de política urbana vigente no país impera a "ambiguidade constitutiva" já largamente identificada por historiadores e cientistas políticos como marca da política brasileira, ambiguidade que "produz fórmulas combinatórias entre o 'real' e o 'legal', o 'público' e o 'privado', reinventando suas fronteiras, mas trabalhando na direção de sua manutenção" (GOMES, 1998, p. 502 apud ROLNIK, 2009, p. 37)

23 Este livro, publicado em 2015, é muito atento à realidade brasileira e já naquele momento nos dava pistas para compreender como a política urbana do momento hegemônico do governo do Partido dos Trabalhadores foi uma política anticíclica que promoveu um ajuste espacial (HARVEY, 2006), para afastar a crise do subprime de 2008. Entretanto este livro nos mostra que esse modelo - que é maior que a política urbana, mas ela está contida nele - dá sinais de profundo esgotamento. Os acontecimentos recentes infelizmente mostram que não conseguiremos afastar a crise política e econômica.

24 A autora reconhece como as políticas de aumento salarial e de criação de programas sociais foram um enorme avanço na história brasileira; entretanto, como os aumentos dos ganhos salariais são absorvidos por uma cidade cada vez mais cara, a atual crise urbana tem absorvido os ganhos sociais que foram construídos nos últimos anos.

Mesmo nessa conjuntura adversa para todos aqueles que querem construir uma outra cidade - uma cidade como "direito à vida urbana" (LEFBRVE, 2006 p.117), uma cidade justa que aceita as diferenças -, a autora aponta algumas questões que são caras para vários movimentos sociais em prol da reforma urbana. São trincheiras que teremos que lutar nos próximos anos, ao mesmo tempo em que conformam uma agenda de pensamento sobre os desenvolvimentos da cidade contemporânea que teremos que nos debruçar. 


\section{BIBLIOGRAPHY}

BOTELHO, Maurilio Lima. Desenvolvimento, espaço e crise estrutural. Espaço e Economia: Revista Brasileira de Geografia Econômica, Ano I, Número 2, Janeiro / Junho de 2013. Disponível em: http:// espacoeconomia.revues.org/153. Acesso em: 25 de março de 2016.

HARVEY, David. O ajuste espacial: Hegel, Von Thünen e Marx. In: HARVEY, David. A produção capitalista do espaço. São Paulo: Annablume, 2006.

HARVEY, David. O Neoliberalismo: história e implicações. Tradução: Adail Sobral e Maria Stela Gonçalves. São Paulo: Edições Loyola, 2008.

IANNI, Octavio. A questão nacional na América Latina. Estudos Avançados, versão On-line. v.2 n.1 São Paulo jan/mar. 1988. Disponível em: http://www.scielo.br/scielo.php? script=sci_arttext\&pid=S0103-40141988000100003. Acesso em: 05 de Abril de 2016.

LAMAS, Bruno. A “explosão da cidade" e a trajectória do capitalismo. Disponível em: http:// www.obeco-online.org/bruno_lamas2.htm. Acesso em: 05 de Abril de 2016.

LEFEBVRE, Henri. o Direito à Cidade. São Paulo, Centauro, 2006.

MARICATO, Ermínia. Erradicar o analfabetismo urbanístico. Disponível em: http://www.usp.br/ fau/depprojeto/labhab/biblioteca/textos/maricato_analfabetismourbano.pdf. Acesso em: 25 de março de 2016.

MARICATO, Ermínia. Impasse da política urbana no Brasil. Petrópolis: Vozes, 2011.

MARICATO, Ermínia. Para entender a crise urbana. São Paulo: Expressão Popular, 2015.

ROLNIK, Raquel. Democracia no fio da navalha: limites e obstáculos para a implementação de uma reforma urbana no Brasil. Revista Brasileira de Estudos Urbanos e Regionais (ANPUR), v. 11, p. 31-50, 2009. Disponível em: http://www.urbanismo.mppr.mp.br/arquivos/File/2194063PB.pdf. Acesso em: 10 de março de 2016 .

ROLNIK, Raquel. Guerra dos lugares: a colonização da terra e da moradia na era das finanças. São Paulo: Boitempo, 2015.

OLIVEIRA, Francisco de. Crítica à Razão Dualista - O Ornitorrinco. 2. a ed. São Paulo: Boitempo, 2003.

SMITH, Neil. Desenvolvimento desigual: natureza, capital e a produção do espaço. Rio de Janeiro: Bertand Brasil, 1988.

SMITH, Neil. ¿Ciudades después del neoliberalismo?. In: SMITH, Neil; ROLNIK, Raquel; ROSS, Andrew; DAVIS, Mike. Después del neoliberalismo: ciudades y caos sistémico. Barcelona: Ed. MACBA/ UAB, Universitat Autónoma de Barcelona, 2009.

\section{NOTES}

1. Ver Maricato (2016), texto em a que autora explora este tema.

2. Para uma resumo da vasta bibliografia sobre os efeitos do neoliberalismo sobre as cidades e a sua crítica, ver Harvey (2008), Smith, (2009) e Rolnik (2015).

3. "O exemplo disso foi o fordismo: ao mesmo tempo que a linha de montagem reduzia o tempo de trabalho para cada mercadoria, permitia também a absorção de maiores quantidades absolutas de força de trabalho. $\mathrm{O}$ resultado foi uma sociedade do trabalho a todo o vapor, o arranque da 
urbanização mundial generalizada e o progressivo embaratecimento generalizado de mercadorias inicialmente vendidas como bens de luxo (automóvel, frigoríficos, máquinas de lavar, etc.)" (LAMAS, 2016).

4. "Não há mais uma fronteira externa para expansão capitalista - a unificação do mundo pelo mercado chegou ao fim. Ainda que possa existir uma ou outra área do planeta ainda não totalmente incorporada ao mundo da mercadoria e do dinheiro, a dimensão dessas áreas não é suficiente para resgatar o capitalismo e colocá-lo num novo ciclo de expansão. Assim, o capitalismo chegou ao seu limite de expansão geográfica externa: não há mais possibilidade de criar um novo mercado externo para salvá-lo dessa condição crítica. A globalização representa, portanto, o ápice desse processo de expansão geográfica externa, para além do qual não há mais exterioridade. Isso tem uma série de implicações ainda, inclusive em termos ecológicos (externalização de custos) e econômicos (formação de um mercado de força de trabalho mundial unificado), mas destaquemos esse limite geográfico importante: não há mais saída externa para a expansão dos mercados. Se há superacumulação de capital ou superacumulação de mercadorias, não é possível mais escoar para fora o excedente realizado no passado." (BOTELHO, 2013).

5. Para compreender o que a autora chama de "impasse da política urbana", ver: Maricato, 2011.

\section{AUTHORS}

\section{ARIANE MELCHIOR NUNES DA HORTA}

Graduada em Geografia pela UFRRJ - Universidade Federal Rural do Rio de Janeiro. E-mail: arianehorta.geo@gmail.com.

\section{GUILHERME CHALO NUNES}

Formando em Geografia pela UFRRJ - Universidade Federal Rural do Rio de Janeiro. E-mail: guilhermechalo@gmail.com. 